Revista lus et Praxis, Año 24, No 3, 2018, pp. 583 - 618

ISSN 0717 - 2877

Universidad de Talca - Facultad de Ciencias Jurídicas y Sociales

El contrato de servicios como categoría general en el derecho chileno.

Su contenido y rasgos distintivos

María Graciela Brantt Z. - Claudia Mejías Alonzo

Trabajo recibido el 4 de agosto de 2017 y aprobado el 28 de septiembre de 2018

\title{
El contrato de servicios como categoría general en el derecho chileno. Su contenido y rasgos distintivos ${ }^{*}$ \\ The SERVICE CONTRACt AS a General CATEGory for ChILEAN LAW. ITS CONTENT AND DISTINCTIVE FEATURES
}

\author{
María Graciela Brantt Z.** \\ Claudia Mejías Alonzo**
}

\begin{abstract}
RESUMEN
Este trabajo estudia el contrato de servicios y propone una noción como categoría general para el derecho chileno. Asimismo, examina sus características distintivas. Se busca contribuir a la configuración de su régimen jurídico, necesario por la falta de una disciplina legal especialmente dedicada a esta figura.
\end{abstract}

\section{ABSTRACT}

The aim of this paper is to study the services contract and to propose a definition for it, which works as a general category for Chilean law. Furthermore, the paper examines distinctive features of the contract under analysis. The general goal of this work is to contribute to the shape of its legal regime. This is necessary due to the lack of a legal discipline especially formulated for this figure.

$$
\begin{gathered}
\text { PALABRAS CLAVE } \\
\text { Contrato, servicios, derecho chileno }
\end{gathered}
$$

KEY WORDS

Contract, services, chilean law

\section{Introducción}

Los contratos de servicios, desde hace un tiempo, han sido objeto de preocupación en el ámbito comparado y, más recientemente -aunque con menos intensidad' ${ }^{1}$-también para los autores nacionales. El interés por ellos deriva de la

\footnotetext{
* El presente trabajo es parte de los resultados del proyecto Fondecyt Regular número 1160469 del que las autoras son, respectivamente, investigadora responsable y co-investigadora.

** Profesora de derecho civil, Pontificia Universidad Católica de Valparaíso, Valparaíso, Chile. Correo electrónico maria.brantt@pucv.cl

${ }^{* * *}$ Profesora de derecho civil, Pontificia Universidad Católica de Valparaíso, Valparaíso, Chile. Correo electrónico claudia.mejias@pucv.cl

1 Por el escaso interés existente en nuestro derecho por los contratos de servicios Barros los ha calificado como "el pariente pobre del derecho de obligaciones y contratos". BARros (2012), p. 326.
} 
constatación de su importancia en el tráfico jurídico, atendido que el desarrollo económico ha llevado a la proliferación de relaciones jurídicas que encuadran en lo que genéricamente denominamos servicios. Tal circunstancia ha puesto de manifiesto la necesidad de dedicar esfuerzos a su estudio y análisis.

En este escenario, nuestro derecho -como acontece en la mayoría de los ordenamientos jurídicos- carece de una regulación especial que se haga cargo de las particularidades que presentan estos contratos ${ }^{2}$, toda vez que el modelo que ha ocupado el interés de nuestros legisladores decimonónicos y de la doctrina en general ha sido la compraventa ${ }^{3}$. Por lo anterior, suele caracterizarse a los contratos de servicios como atípicos, por la carencia de un cuerpo orgánico de disposiciones destinado particularmente a ellos ${ }^{4}$. Tal circunstancia hace necesario, por consiguiente, precisar la normativa que resulta analógicamente aplicable con la finalidad de construir su régimen jurídico.

Para una primera aproximación a la definición de dicho régimen, es posible acudir a la legislación civil, general y especial, que en alguna medida conecta con el ámbito de los servicios. Así, en la legislación general podemos atender, como regularmente lo ha destacado nuestra doctrina, a la reglamentación del

\footnotetext{
2 Así lo destaca en el ámbito europeo -en un comentario válido también para el contexto latinoamericano- Loos. El autor, a propósito de la elaboración, por parte del Grupo de Estudio sobre un Código Civil Europeo, de los Principios de Derecho europeo, en su parte especial destinada a los contratos de servicios (en adelante PEL SC, por su sigla en inglés) y del Borrador del Marco Común de Referencia (en adelante, DCFR, por su sigla en inglés) que tomó como modelo el primero, afirma que por largo tiempo los servicios han sido un área subdesarrollada del derecho, subrayando que no obstante existir varias codificaciones que contienen disposiciones que podrían servir de base para un sistema general de servicios (como ocurre con el BGB y el Code), muchas de esas normas son rudimentarias; $y$, por otro lado, cuando existen normas de alcance más general, resultan poco exhaustivas. Agrega que, en rigor, ni a nivel nacional ni europeo existe, un cuerpo coherente de normas para los contratos de servicios. Loos (2011), p. 757. En el derecho español, y a propósito de la inclusión de los servicios en el arrendamiento -algo que ocurre también en nuestro Código Civil, como es sabido- Ortega plantea que "cabe cuestionarse si los contratos de servicios únicamente se ajustan a los estrechos ropajes del arrendamiento", afirmando además, que el Código Civil español menciona de manera extremadamente escueta e insuficiente al contrato de servicios. OrTEGA (2008), pp. 222-223. También en España, Escartín alude a "la relativa insuficiencia del actual Derecho Civil y Mercantil codificado para dar respuesta a la problemática actual de los contratos de servicios". EsCARTín (2012), p. 608.

3 Barros resalta el rol de la compraventa como modelo sobre el que se construyó la doctrina del contrato, lo que afirma se ha manifestado incluso en el desarrollo más reciente de la materia, con la indiscutible influencia de la compraventa internacional de mercaderías regulada en la Convención de Viena. BARROS (2012), pp. 325 y 326.

${ }^{4}$ Destaca el carácter atípico: Rodrícuez (2014), p. 794. La autora recalca que a pesar de carecer de un régimen especial como tales en el Código Civil y en el de Comercio, cuentan eso sí con tipicidad social o de tráfico, desde que son reconocidos como una categoría contractual incluso jurisprudencialmente. En la misma línea de resaltar la atipicidad, aunque en un terreno más acotado de los servicios: PizARRo (2014), pp. 827-829. El autor, refiriéndose a las características del contrato médico, expresa que estamos ante una prestación de servicios y que, como tal contrato, es atípico.
} 
contrato de arrendamiento, en especial, de servicios inmateriales y confección de obra material, sin perjuicio de las reglas sobre arrendamiento de transporte; $y$, por otro lado, al contrato de mandato, que incluso se ha afirmado debe ser considerado el estatuto supletorio por excelencia ${ }^{5}$.

Fuera del Código Civil, en la legislación especial encontramos también disposiciones que se aplican a algunos aspectos y en ciertos ámbitos a los contratos de servicios. En este sentido, destaca la Ley № 19.496 sobre Protección de los Derechos de los Consumidores la que, aunque dedica el Párrafo $4^{\circ}$ del Título III a dictar reglas especiales en materia de prestación de servicios, no los regula en realidad de manera orgánica y completa 6 . Junto con lo anterior, la doctrina nacional también ha mencionado como cuerpos normativos a considerar, en ciertos ámbitos más específicos de servicios o en ciertas materias dentro los mismos, la Ley N² 20.584 sobre derechos y deberes de los pacientes; el Código Sanitario, el Código Orgánico de Tribunales, la Ley General de Urbanismo y Construcción, entre otros ${ }^{8}$.

\footnotetext{
5 RodríGuez (2014), p. 794, afirma que la disciplina normativa de este contrato debe construir con normas dispersas en el Libro IV del Código Civil: las del contrato de confección de obra material, del arrendamiento de servicios inmateriales y del arrendamiento de transporte; a los que se agregan las del mandato y el depósito remunerado. Por su parte, Barros propone que los contratos de servicios que carecen de regulaciones especiales deben regirse analógicamente por las reglas del mandato en cuanto se ajusten a su naturaleza, sin perjuicio de serles aplicables también las escasas normas sobre arrendamiento de servicios inmateriales. El autor distingue en los contratos de servicios entre aquellos en los que el riesgo de la obtención del resultado es del cliente y aquellos en que lo es del deudor -lo que no es otra cosa, aunque no lo dice explícitamente, que distinguir entre contratos de servicios que dan lugar a obligaciones de medios y de resultado-, en donde para los primeros entiende que la normativa supletoria más idónea es la del mandato mientras que, para los segundos, las del contrato de obra. BARROS (2012), pp. 331 y ss. Tal distinción pasa por entender que el carácter de medios o resultado de la obligación incide en diversos aspectos que van más allá de la sola determinación del (in) cumplimiento -cuestión que no compartimos-, lo que no impide reconocer que las reglas del contrato de mandato y de obra pueden aportar para la configuración del régimen de los servicios, sea que dé lugar a una obligación de medios o de resultado.
}

${ }^{6}$ En efecto, esta ley no nos proporciona una regulación completa del contrato de servicios en materia de consumo. Se centra en realidad en los contratos de servicios de reparación y luego, desde una perspectiva más general, en los remedios con que cuenta el consumidor en caso de incumplimiento. Además, en otro párrafo reglamenta los Ilamados servicios financieros, lo que conduce a una separación dentro de la ley entre contratos de servicios no financieros y contratos de servicios financieros. Contardo (2013), pp. 853 y 857. Respecto del enfoque del párrafo $4^{\circ}$ del Título III de la Ley, el autor expresa: "[...] la LPDC en vez de regular los servicios de consumo masivo con generalidad estableciendo su conceptualización general, deberes y obligaciones generales de las partes, prefirió regular un caso específico, la reparación". Por ello, califica como deficiente la técnica legislativa empleada.

7 Pizarro la destaca como una normativa que introduce un contenido imperativo al contrato de servicios médicos. PizArro (2014), p. 830.

${ }^{8}$ Estos últimos cuerpos normativos son mencionados por Baraona como leyes especiales que resultan aplicables a los servicios profesionales, de abogados, arquitectos y proyectistas, así como a ciertos 
A nuestro juicio, ninguno de los conjuntos normativos aludidos proporciona por sí solo un régimen supletorio propiamente tal para estos contratos, sino más bien reglas aisladas susceptibles de regular algunos aspectos. En este escenario, consideramos que reviste gran importancia y utilidad volver la mirada sobre la regulación que proporciona todo el Libro IV del Código Civil, en la que podemos advertir reglas generales que luego son reiteradas en la regulación particular de los contratos 9 . No coincidimos con la idea que se ha planteado en el sentido de que esas normas generales no resultan aplicables a los servicios, porque responderían al modelo tradicional de la compraventa ${ }^{10}$. Creemos más bien, que en esta materia es posible acudir a un derecho común que nos permita integrar el vacío que claramente se advierte en la reglamentación de los contratos de servicios. Por derecho común nos referimos al acervo que la dogmática jurídica ha construido a lo largo de su desarrollo, que obra como dogma en la materia y en la que necesariamente debe apoyarse cualquier solución jurídica para que pueda ser considerada coherente en el ordenamiento jurídico. Derecho común que, por cierto, se sustenta en las reglas legales vigentes, pero también en principios generales, así como otros presentes en cada una de las áreas específicas del derecho. Tales reglas y principios están contenidos y/o manifestados, como indicáramos, a lo largo de todo el Libro IV, y es por esto que no resulta adecuado, para regular sistemáticamente los contratos de servicios, aplicar solo un conjunto de reglas, por ejemplo, las del mandato o del contrato de arrendamiento de servicios que, además, son claramente insuficientes.

Nos parece necesario precisar que no pretendemos la construcción del régimen a partir de una mixtura de disposiciones legales que obedecen a contratos

profesionales del área de la salud (médicos, odontólogos, químicos y farmacéuticos, entre otros) y más concretamente, a la responsabilidad en dicho terreno. BARAONA (2006), p. 31. En el caso del artículo 18 de la Ley General de Urbanismo y Construcción, resulta conveniente precisar que en lo que refiere a la responsabilidad del propietario primer vendedor que allí se regula, no se está en el terreno que aquí interesa, por cuanto en tal caso el contrato celebrado es una compraventa. Tratándose de los restantes profesionales aludidos en la norma respectiva: arquitectos, constructores, proyectistas, etc., sí existe una relación de servicios respecto de quien encargó la construcción, y en tal sentido corresponde tener en cuenta las reglas sobre responsabilidad que contempla la disposición aludida en lo referido al contrato de servicios. Sobre los tipos de relación jurídica que caben en dicho precepto: WAHL (2006), pp. 7 y ss.

9 Sobre el particular: BrantT y Mejías (2016), pp. 71 y ss.

10 En tal sentido se pronuncia Severin cuando, refiriéndose a la construcción del contrato de servicios en el DFCR, expresa que un aporte de dicha regulación consiste en que puede ofrecer un contrapunto al modelo que la compraventa ha sido en general en materia de contratos, particularmente en el caso europeo, la regulada en la Convención de Viena, poniendo en duda que sus soluciones sean generalizables a otra clase de contratos, particularmente los de servicios. Al entender que las reglas generales en materia de obligaciones de nuestro Código Civil están pensadas también para la compraventa, la conclusión sería similar en nuestro derecho. SEVERIN (2014), pp. 192 y ss. 
de distinta naturaleza, sino de aplicar aquellas reglas de derecho común y transversales, que reflejen los elementos compartidos que permiten atribuir ciertas consecuencias jurídicas a la categoría. Por ello, resulta fundamental precisar la noción y características del contrato de servicios como tal, porque a partir de ellas podremos determinar las reglas pertinentes y avanzar así en la configuración de su régimen jurídico.

La primera tarea entonces, será la de delimitar la noción misma de contrato de servicios, de modo de perfilar la categoría contractual a la cual se le aplicará el régimen jurídico supletorio que se termine por construir. Ello implica examinar y hacerse cargo de dos aspectos fundamentales que constituyen la base necesaria para fijar los contornos de la noción. Por una parte, la definición del objeto del contrato, esto es, lo que debemos entender por servicio, por tratarse de su prestación central; y por otra, precisar los rasgos distintivos de esta categoría contractual, aquellas particularidades que lo distinguen de otro tipo de contratos y que pueden generar consecuencias jurídicas propias.

Desde ya, cabe apuntar que no se intenta proporcionar una definición rígida de la figura que desconozca la inmensa variedad de servicios que la práctica contractual muestra diariamente ${ }^{11}$, sino de arribar a una noción general a partir de los elementos que permitan configurar una base mínima y común para calificarlos de tal. En consecuencia, nuestra intención es contribuir a la definición de una categoría amplia y flexible, que permita la incorporación de las diversas actividades que se insertan en la idea de servicios y, al mismo tiempo, determine la procedencia del régimen jurídico aplicable ${ }^{12}$. La diversidad de supuestos que se pueden comprender en su ámbito contractual no difumina la figura como tal $^{13}$.

11 No desconocemos la amplitud de posibilidades que entregan los servicios en el terreno práctico. Como expresa Valpuesta, refiriéndose a la categoría en el DFCR: "Los 'servicios' constituyen una categoría negocial básica, que tiene como centro la realización de una actividad del sujeto obligado [...]. Después, el contenido concreto de esa conducta, la finalidad económica y social perseguida por quien actúa, puede ser muy diversa". VAlPUESTA (2011), p. 256.

12 En tal sentido, compartimos la idea de fondo expresada por De Barrón cuando al referirse a la forma de abordar la regulación de este contrato en el derecho español plantea: "A mi entender, la reforma del Código civil español sólo debería abarcar la regulación sistemática y completa del tipo contractual general, de la categoría jurídica que se encierra dentro del concepto de contrato de servicio, sin pretender aprisionar dentro de esta regulación civil algunos o todas las variedades de servicios que nuestra sociedad puede llegar a demandar". De BARRÓN (2011), p. 13. Si bien nuestra intención no es proponer una reforma legal -sin perjuicio de que pueda ser conveniente- sino una lectura adecuada de las normas generales y especiales existentes para arribar a un régimen jurídico adecuado para los contratos de servicios, compartimos la idea de construir dicho marco a partir de una categoría general y flexible.

${ }^{13}$ En tal sentido se expresa Trigo (1999), p. 146. La autora aborda la cuestión de una posible categoría unitaria de contrato de servicios en el derecho español y el obstáculo que constituiría para ella la enorme variedad de actividades que se comprenden en dicho terreno, que impediría la unidad de 
El enfoque del análisis que realizaremos viene dado por el derecho general, fundamentalmente el Código Civil. No profundizaremos en la legislación de consumo porque proporciona una normativa que se centra en las características de una relación particular y asimétrica, como es la que se da entre proveedor y consumidor ${ }^{14}$. Tendremos también en consideración el modelo del derecho europeo armonizado, en especial del DFCR y los PEL SC, por constituir el producto de una reflexión detenida sobre esta categoría, que indudablemente lo convierte en referencia. De hecho, tomaremos de allí también la nomenclatura de cliente y prestador de servicios, porque esta es además la que usualmente se emplea en el tráfico jurídico, incluso el nacional.

El trabajo se dedicará a continuación al examen del servicio como la prestación central de este contrato, para luego, en una segunda parte, revisar los rasgos distintivos que, a nuestro juicio, presenta la categoría contractual en estudio. Finalizaremos con unas conclusiones.

\section{La prestación central y la categoría general del contrato de servicios}

Como anticipamos, lo primero que parece necesario dilucidar, si se trata de estudiar este contrato, es precisamente lo que constituye el objeto de la obligación que asume el prestador del servicio. ¿Cuál es el contenido de su obligación? ¿En qué consiste la prestación en estos casos?

En nuestro derecho no contamos con una definición de contratos de servicios ni de los servicios como tales, a pesar de que el legislador emplea este último término tanto en el Código Civil ${ }^{15}$ como fuera de él. En efecto, en el Código Civil nos encontramos con que el artículo 1915, al definir el contrato de arrendamiento contempla, como uno de sus posibles objetos, que una de

todas dichas hipótesis en dentro de una figura contractual, idea que rebate afirmando que el contrato de servicios "cuenta con entidad propia en parámetros jurídicos y económicos".

14 El contrato de servicios que nos interesa analizar presupone que las partes están situadas en un plano de igualdad y han podido negociar su contenido, sin perjuicio de realizar alguna referencia a la legislación de consumo que pueda ser de utilidad en la construcción que queremos proponer. En tal sentido, también conviene apuntar de inmediato que nuestro objeto de examen no lo constituyen los servicios estandarizados, esto es, aquellos que responden a la lógica de la oferta de prestación de actividades de manera masiva y no personalizada, que son, por cierto, los que predominan en el derecho de consumo.

Tampoco nos centraremos en la regulación mercantil, lo que no impide apuntar que el escenario es bastante similar en dicho terreno en cuanto a la falta de sistematicidad para regular esta categoría contractual. Sobre la cercanía de ambos órdenes contractuales se pronuncia, en un sentido aplicable a nuestro derecho, TRIGO (1999), p. 152.

15 Esta circunstancia no es exclusiva de nuestro ordenamiento jurídico. En efecto, en España se aprecia que el legislador se refiere a los servicios en los artículos 1254, 1271 y 1272 del Código Civil como posible objeto de los contratos, pero no entrega una definición de los mismos. 
las partes se obligue a prestar un servicio. Y luego, en la regulación particular de esa clase de arrendamiento, en los artículos 2006 y siguientes, se desprende que los servicios inmateriales son entendidos por el legislador como aquellos en que predomina la inteligencia por sobre la obra de mano, limitándose dicha norma, así como el artículo 2007, a mencionar diversos ejemplos de tal clase de servicios, pero sin detenerse en definir qué entiende por tales.

En la misma dirección encontramos otras disposiciones. El artículo 2118 dispone que ciertos servicios (los de profesiones y carreras que suponen largos estudios, así como aquellos a que esté unida la facultad de representar y obligar a otra persona respecto de terceros), quedan sujetos a las reglas del mandato. Por su parte, el artículo 2219 en materia de depósito prevé que si se estipula remuneración por la custodia de la cosa, el contrato degenera en arrendamiento de servicios, refiriéndose al depositario como quien presta el servicio que -según se desprende de los términos del precepto- consiste precisamente en custodiar la cosa, siendo esa la única idea que la norma entrega sobre lo que sería el servicio.

Lo mismo ocurre en diversas disposiciones contempladas en materia de donaciones (artículos $1396^{16}$ y siguientes) y también en algunas cauciones como la prenda (artículo $2388^{17}$ ) y fianza (artículo $2341^{18}$ ), en el contrato de sociedad (artículo 206919) e incluso, en materia de prescripción extintiva (artículo 2522 inciso segundo ${ }^{20}$ ), en que se emplea la expresión servicios sin delimitar su concepto ${ }^{21}$.

${ }^{16}$ Esta disposición establece: "Los servicios personales gratuitos no constituyen donación, aunque sean de aquellos que ordinariamente se pagan". En los preceptos referidos a las donaciones remuneratorias (artículos 1433 y siguientes) también se emplea la expresión servicios.

17 En este artículo se aprecia el uso de la expresión servicio para aludir a aquello que realiza el tercero en favor del deudor al constituir la prenda como garantía de su obligación. Así se desprende su texto: "La prenda puede constituirse no sólo por el deudor sino por un tercero cualquiera, que hace este servicio al acreedor".

${ }^{18}$ En esta disposición, en sentido similar a la anterior, el legislador denomina servicio a aquello que hace quien constituye la fianza a favor del deudor, contemplando la posibilidad de que se pacte una remuneración por el mismo. Lo confirma su tenor: "El fiador puede estipular con el deudor una remuneración pecuniaria por el servicio que le presta".

${ }^{19}$ El servicio lo constituye, según este precepto, aquello que puede aportar un socio a la sociedad.

20 Esta regla fija el plazo de prescripción de las acciones para el cobro del precio de los servicios que se prestan periódica o accidentalmente ciertas personas, fijándose como ejemplos los posaderos, barberos, entre otros.

${ }^{21}$ Cabe consignar que en la Ley № 19.496 se aprecia algo similar a lo que ocurre con el Código Civil, por cuanto se emplea reiteradamente la expresión servicios pero tampoco se contiene una definición de los mismos. Así lo destaca Contardo cuando expresa: "A pesar de que la ley definió varias pala- 
Conforme a lo expuesto, y tal como ha expresado en España Villanueva Lupión, en una idea perfectamente válida también para nuestro sistema, los servicios aparecen en la legislación como una categoría residual o, dicho de otra forma, parece que son tales aquellas prestaciones que no sean dar una cosa en la terminología del Código Civil o lo que no constituya un bien en la nomenclatura del derecho de consumo 22 .

De esta forma, parece indispensable darle contenido a la noción de servicio como el objeto central del contrato que nos interesa. En dicha labor, una primera aproximación puede realizarse desde la perspectiva económica, especialmente considerando que, como adelantamos, es la relevancia de los servicios en dicho terreno lo que plantea la necesidad de estudiarlos desde el derecho.

En el plano económico los servicios aparecen, junto con los bienes, como objetos de las transacciones que se realizan en el mercado ${ }^{23}$, y en dicho contexto, como ha destacado Severin, la definición económica de lo que es un servicio se ha hecho tradicionalmente "en forma negativa, a partir de la ausencia de alguna de las características o propiedades que se atribuyen a los "bienes", principalmente la materialidad. Así, los bienes suelen ser descritos como productos materiales o tangibles, mientras que los servicios son conceptualizados como productos inmateriales o intangibles" 24 . En el mismo sentido, otro autor ha expresado: "en economía los bienes son objetos tangibles y todo lo que se comercia y no es bien entra en el epígrafe de servicio" ${ }^{25}$, poniendo además de relieve el carácter residual que tiene la noción en dicho ámbito. Como sea, lo que destaca desde esta perspectiva es que los servicios aparecen en una función y con un tratamiento similar a los bienes, como objetos de un intercambio que satisface necesidades en el mercado. En consecuencia, así como a cambio de un precio se adquieren bienes, también se pueden adquirir

bras de uso común en la misma en el art. $2^{\circ}$ (sic), no cuidó en definir qué se entiende por "servicio". Contardo (2013), p. 853.

22 Villanueva (2009a), pp. 35 y ss. y 106 y ss. En sentido similar se expresa Loos, cuando comentando la definición de contrato de servicio en el DCFR, afirma que algo que en general ocurre en los sistemas que no cuentan con una definición de servicio, es que es vista como residual, de modo que si no se clasifica en una venta, arrendamiento o contrato de trabajo, es considerado como servicio o una obligación sui generis. Loos (2011), p. 764.

${ }^{23}$ Véase: Pindick y RUbinfeld (2009), p. 9.

${ }^{24}$ Severin (2014), p. 194, nota 363. Lo destacado es del autor, quien resalta que, si bien se han propuesto otros criterios para distinguir entre bienes y servicios, todos ellos se encuentran asociados a la tangibilidad.

${ }^{25}$ TJONG TJIN TAI (2010), p. 6. 
servicios, lo que pone en evidencia la asimilación de ambos en cuanto a su función en el mercado.

Esta visión económica del servicio no es ajena al derecho, de hecho es la que subyace en el derecho de consumo, ámbito en el que además se origina el interés por los servicios desde el terreno jurídico. En ese contexto, estos aparecen contrapuestos a los bienes o productos como objetos de la contratación. El proveedor ofrece y el consumidor adquiere bienes o servicios a cambio de un precio ${ }^{26}$. Esta concepción resulta bastante lógica si se considera que una buena parte de los servicios que se prestan en ese contexto corresponde a unos estandarizados, que por lo mismo, resultan fácilmente asimilables a la idea de bien o producto susceptible de ser adquirido a cambio de un precio ${ }^{27}$.

Con todo, y sin perjuicio de la recepción por el derecho de la noción económica de servicio, cabe preguntarse si es posible mantenerla en el terreno jurídico, considerando que lo que aquí interesa es examinarlos como parte de una relación contractual, como la prestación a la que se obliga una de las partes. Y en tal sentido, parece que la noción jurídica de servicio no puede identificarse simplemente con un objeto que se intercambia por un precio, de la misma manera que los bienes o $\operatorname{cosas}^{28}$. Tal equiparación, propia del terreno económico, no se condice con la función que les corresponde en el plano jurídico. En este, el servicio se presenta como algo diverso, que va más allá de ser un mero objeto de intercambio y que debe ser dotado de contenido propio. Y ello es lo que nos interesa aclarar en lo sucesivo.

Situados en esta función jurídica, esto es, de los servicios en el seno de una prestación, lo primero que resulta claro y sobre lo que existe concordancia, es que su incorporación como objeto de un contrato da lugar a una obligación de hacer ${ }^{29}$, es decir, pertenecen a aquella categoría de obligaciones cuyo

\footnotetext{
${ }^{26}$ Esta asimilación es destacada por Villanueva, quien usa la expresión "cosificación de los servicios" para denotarla. Villanueva (2009a), pp. 41 y ss. y 55 y ss. Esta concepción de los servicios se advierte también en la normativa de la Ley $\mathrm{N}^{0}$ 19.496, que en varios aspectos da un tratamiento similar a bienes y servicios, considerando a ambos objetos de similar naturaleza en la contratación de consumo.

27 Tjong plantea que es necesario distinguir entre aquellos servicios individualizados y aquellos que no revisten tal carácter, siendo estos últimos susceptibles de ser tratados como productos. TJONG TJIN TAl (2010), pp. 8 y ss.

Otro caso de concepto económico recogido en el terreno jurídico se advierte en el derecho comunitario europeo, en la Directiva de servicios en el mercado interior, 2006/123/CE, que entiende por servicio en su artículo $4^{\circ}$ : "cualquier actividad económica por cuenta propia, prestada normalmente a cambio de una remuneración, contemplada en el artículo 50 del Tratado".

28 Así se observa en SeVErin (2014), p. 196. El autor expresa que en la literatura económica moderna se ha cambiado la visión para postular la autonomía de la noción de servicio respecto de la de bien.

${ }^{29}$ Ya en la década de los setenta, en España, Moreno Quesada destacaba los servicios como obligaciones de hacer que merecían especial atención. Moreno (1976), p. 467. También Villanueva afirma que "los
} 
objeto consiste en la ejecución de un hecho cualquiera, según la definición tradicional de las mismas. Como expresa Ortega, los contratos de servicios se caracterizan "porque la prestación o comportamiento que debe realizar uno de los contratantes consiste, fundamentalmente, en el despliegue de cierta actividad, material o intelectual" 30 .

En el derecho armonizado de contratos en Europa, se aprecia algo similar. Tanto el DFCR, como su fuente principal en materia de servicios, los PEL SC, así como los comentarios oficiales a sus respectivos articulados, muestran que la idea de servicio que recogen tiene como eje central, justamente, una actividad que debe desplegar el deudor.

En efecto, en los comentarios oficiales al artículo 1:101 de los PEL SC, cuyo párrafo (1) define los contratos de servicios ${ }^{31}$, se afirma que la obligación de proveer un servicio se impone cuando un prestador realiza un trabajo ("perfoms work" se dice textualmente), de acuerdo con las específicas necesidades e instrucciones de la otra parte, el cliente. Junto con ello, se dan como ejemplos de servicios comprendidos en tal noción actividades tan variadas como las de arquitectos, bancos, abogados, carpinteros, jardineros, entre otros ${ }^{32}$. Y refiriéndose al servicio mismo, se expresa que éste puede ser descrito como un proceso por el cual el prestador realiza un trabajo de acuerdo con los particulares deseos y necesidades del cliente en orden a alcanzar un resultado ${ }^{33}$. De hecho, es recurrente el uso de la expresión "proceso de servicio" para aludir a lo que el deudor debe realizar para cumplir el contrato ${ }^{34}$. Tratándose del DFCR, De Barrón afirma que el planteamiento básico en el mismo es que

servicios constituyen uno de los objetos de la prestación de hacer". Villanueva (2009a), p. 281. Igualmente afirma tal carácter de los servicios: Díez-Picazo (2008), p. 279. En Chile, RodríGuez (2014), p. 794.

30 Ortega (2008), p. 232.

31 El artículo dispone en su párrafo (1): "This Chapter applies to contracts whereby one party, the service provider, is to supply a service to the other party, the client, in exchange for remuneration".

32 Comentario A. (Idea general) al artículo 1:101. Barendrecht et al. (2007), p. 140.

33 Comentario A al artículo 1:106. BARENDRECHt et al. (2007), p. 202.

34 En los comentarios oficiales al articulado de los PEL SC es frecuente la idea del servicio entendido como proceso. Así se aprecia, por ejemplo, en los comentarios A y B al artículo 1:105 (que regula las circunstancias que debe considerar el prestador del servicio para la ejecución del mismo); en el comentario $\mathrm{A}$ al artículo 1:106 (que regula una serie de deberes impuestos al prestador del servicio en la ejecución del mismo, como dicen los comentarios textualmente: "This Article imposes duties upon the service provider with respect to the service process itself" [...]); en el comentario A al artículo 1:107 (que regula el estándar de cuidado y diligencia exigibles en la ejecución del servicio). BARENDRECHT et al. (2007), pp. 196 y ss. 
los servicios generan una obligación jurídica de hacer ${ }^{35}$. De esta forma, en los textos aludidos el servicio es entendido como un hacer que el prestador compromete en virtud del contrato.

Ahora bien, es preciso avanzar en orden a perfilar de un modo más concreto ese hacer al que se obliga el prestador del servicio. Las obligaciones de hacer pueden recaer sobre un amplio espectro de actividades, pero como hemos anticipado, en los contratos de servicios estamos ante una prestación con ciertas características especiales ${ }^{36}$ que es necesario dilucidar.

De modo previo, sin embargo, parece útil destacar que existen algunos hechos que, no obstante ser el objeto de obligaciones de hacer, no constituyen servicios. Es decir, cabe inicialmente una delimitación negativa de la noción. Ello impone primeramente dejar fuera de esta calificación el hecho objeto de la obligación nacida de un contrato de promesa, porque el hacer en tal supuesto refiere exclusivamente a la celebración del contrato definitivo o prometido. No hay un hacer a favor de otro que, como veremos luego, es el rasgo más distintivo de los servicios.

Asimismo, y aun cuando involucren un hacer, aquellos contratos en que una de las partes encarga a otra la confección de una cosa y quien la elabora aporta la materia principal, tampoco pueden calificarse como de servicios, porque no obstante el hacer que presuponen, el compromiso fundamental asumido por el deudor en tal caso es dar la cosa resultante de su actuación, de modo que no se trata estrictamente de una obligación de hacer. Ello es lo que por lo demás explica la calificación de compraventa que el Código Civil les atribuye en el artículo 1996, pues se trata de contratos que no obstante comprender un hacer, tienen por objetivo central conducir a la transferencia del dominio de la cosa resultante ${ }^{37}$. No ocurre lo mismo, sin embargo, cuan-

${ }^{35}$ De BARRón (2008), p. 15. En igual sentido, Severin afirma: "parece bastante claro que los contratos de servicio, en el modelo del DCFR, tienen por objeto una obligación de hacer: el prestador del servicio asume la ejecución de una tarea o la realización de un trabajo". SEVERIN (2014), p. 272.

${ }^{36}$ En España, Villanueva afirma que son prestaciones de hacer con ciertas peculiaridades. ViLLanueva (2009a), p. 163.

${ }^{37}$ El criterio de la propiedad de la materia principal que recoge nuestro Código Civil tiene sus raíces en el derecho romano y es concordante con la idea de que quien encargó la obra tiene su interés centrado en la adquisición de la cosa resultante de la actividad del artífice, de ahí la calificación de compraventa. Sobre los problemas o interrogantes que igualmente plantea la disposición del artículo 1996: SAN MARTín (2015), pp. 751 y ss. Tratándose del derecho armonizado europeo, se aprecia que el DCFR emplea un modelo según el cual el criterio distintivo en estos casos consiste en si es necesaria o no la transferencia de dominio por parte de quien ha confeccionado la cosa, de modo tal que si lo es, habrán de aplicarse preferentemente las reglas de la compraventa y solo de manera excepcional las de los contratos de servicios. En los PEL SC en tanto, la regla consiste en que los contratos en que una parte debe confeccionar una cosa y luego transferirla a quien la encargó, 
do la materia principal es aportada por quien encarga la obra; en tal caso el interés central del cliente lo constituye la actividad a desplegar por el prestador del servicio, según explicaremos más adelante.

Entrando ahora en la caracterización positiva de la prestación central de los contratos de servicios, un aspecto de especial trascendencia para su construcción jurídica es la consideración de la finalidad perseguida con el hacer que debe desplegar el prestador. El hacer que constituye el servicio tiene un fin determinado: generar un beneficio para el acreedor, es algo que se hace a favor de otro. Este es un elemento que aparece incluso en el significado natural de la palabra servicio. Según la RAE, servicio significa "acción y efecto de servir" y, a su vez, entre los múltiples significados que le corresponden a la voz servir, existen dos que van en la línea de lo aquí afirmado: "estar al servicio de alguien" y "estar sujeto a alguien por cualquier motivo haciendo lo que él quiere o dispone". Quien presta el servicio hace algo a favor o en beneficio de otro -el cliente- que obtiene un cierto provecho de ese hacer.

Esta es además una idea presente también en los textos normativos europeos que se han detenido en la regulación del contrato de servicios. Así se desprende, de los comentarios que se han elaborado de las normas respectivas, los que, como ya señalamos, han recogido la idea de que el deudor del servicio se obliga a "hacer un trabajo" a favor del acreedor. El servicio es concebido como un proceso que se lleva a cabo en utilidad o interés del cliente ${ }^{38}$. Esta particularidad del servicio es fundamental en la construcción jurídica de su noción, por cuanto es la que más fuertemente lo aleja de la idea puramente económica de simple intercambio de hecho por precio y, especialmente, porque su consideración trae aparejada una serie de consecuencias para el contrato en que dicha prestación se inserta.

En efecto, la especial relevancia del beneficio o utilidad que el hacer representa para el cliente permite comprender, por ejemplo, que la determinación del contenido del contrato sea susceptible de ser precisado durante su ejecución, de modo tal que será suficiente con que sus aspectos centrales estén definidos a su celebración. Incluso por dicha circunstancia es perfectamente admisible que

constituyen contratos mixtos de servicios y compraventa. Sobre ambos criterios y sus fundamentos: SeVERIN (2014), pp. 286 y ss.

${ }^{38}$ Como expresa Loos, los contratos de servicios en el DFCR se caracterizan por el hecho que una parte, el proveedor del servicio, hace algo en interés de la otra parte, el cliente. Y agrega que salvo que se trate de servicios estandarizados, el servicio necesita adaptarse a los deseos y necesidades del cliente según fue especificado al celebrar el contrato. Loos (2011), p. 770. Por su parte, Villanueva afirma categóricamente que "Los servicios se prestan siempre para otro que recibe de los mismos una utilidad". Villanueva (2009a), p. 164. 
su objeto inicial experimente modificaciones durante el curso del contrato ${ }^{39}$, las que muchas veces derivan casi exclusivamente de la voluntad del cliente (piénsese, por ejemplo, en la elección de colores, lámparas y otros elementos de decoración que el cliente va seleccionando o modificando durante el desarrollo de un contrato con un decorador de interiores). Ello, sin embargo, no pone en jaque la fuerza obligatoria del contrato, que sigue vigente porque tal posibilidad se explica en esta especial particularidad del hacer contratado.

Otro aspecto relevante para precisar el contenido jurídico de los servicios como una prestación de hacer, es el referido a la relación o conexión que puede darse en ciertos casos entre el hacer debido y una cosa, y, por consiguiente, su delimitación con las obligaciones de dar. Al respecto, conviene primeramente recordar que el artículo 1460 de nuestro Código Civil, refiriéndose al objeto en los actos jurídicos, dispone que "toda declaración de voluntad debe tener por objeto una cosa que se debe dar, hacer o no hacer". A su vez, el artículo 1438, al definir el contrato destaca que por éste "una parte se obliga para con otra a dar, hacer o no hacer alguna cosa". Si bien una primera y somera lectura de estos preceptos podría llevar a concluir que el hacer en cuanto prestación siempre debe referirse a una cosa, ello sin embargo debe descartarse categóricamente porque, como es aceptado unánimemente, el hacer que estas disposiciones contemplan como posible objeto de los contratos es fundamentalmente una actividad, una conducta, un hecho que una parte queda obligada a ejecutar a favor de otra. Por consiguiente, la palabra cosa aparece empleada en ellas en un sentido muy amplio ${ }^{40}$ y no como indicación de una necesaria relación con el hacer comprometido.

Despejado lo anterior, en todo caso, igualmente debemos reconocer que el hacer que se obliga a ejecutar una parte a favor de la otra en muchas ocasiones se encuentra en conexión, en algún sentido, con una cosa, entendida ésta como un objeto material. Y en este punto, aparece una cuestión relevante a la hora de delimitar la noción de servicio: cuando el hacer que debe desplegar el deudor involucra o repercute en cosas materiales, como ocurre, por ejemplo,

\footnotetext{
39 Esto es recogido en la regulación del derecho uniforme europeo. Así, en el DCFR se contienen normas que habilitan, por ejemplo, a dejar ciertos aspectos del contrato abiertos a su celebración; así como que las partes puedan incorporar unilateralmente modificaciones al contrato verificadas ciertas condiciones (artículos 2:107 y 2:109 respectivamente). Sobre el particular: Loos (2011), pp. 770 y ss.

40 Así lo afirma Díez-Picazo quien, refiriéndose al texto del artículo 1126 del Código Civil francés -que se expresa en términos muy similares a los de nuestro artículo 1460- señala que en tal caso se habla de cosa en un sentido amplio, en tanto ellas pueden ser objeto de las obligaciones de dar, pero no de las de hacer o no hacer, las cuales pueden agotarse en el puro servicio, en la simple conducta de la persona, sin que sea necesario que dicho hacer se refiera a una realidad del mundo exterior. Díez-PiCAZO (2007), p. 229.
} 
cuando se debe fabricar o modificar una cosa, o cuando se debe transportarla, custodiarla, repararla, etc. ¿Estamos igualmente ante un servicio, o éste se ve desplazado por la presencia de la cosa? Dicho de otra forma: ¿se trata igualmente de una obligación de hacer?

Al respecto, debe apuntarse que la calificación de obligación de hacer no se pierde por la presencia de una materia o cosa sobre la cual el deudor deba "hacer algo". Como se ha sostenido en doctrina ${ }^{41}$, dentro de las obligaciones de hacer es perfectamente posible distinguir entre aquellas que se agotan en el hecho o actividad, sea intelectual o inmaterial (como enseñar, cantar, asesorar o aconsejar, por dar algunos ejemplos gráficos), y aquellas en que la actividad se vincula con una cosa-como en los casos antes señalados- pero sin que ésta llegue a superar en trascendencia al hecho mismo, pues lo que resulta primordial para el interés del acreedor es el hacer del deudor ${ }^{42}$. Siendo así, se puede afirmar que la presencia de una cosa conectada con la conducta del deudor, incluso si debe ser el resultado de dicha conducta, no impide la calificación como obligación de hacer. En definitiva, puede decirse que la obligación será de hacer en la medida que sea la actividad a desplegar por el deudor lo preponderante para la satisfacción del interés del acreedor o cliente. Eso es lo determinante y es lo que acontece en los llamados contratos de obra. En ellos, la importancia de la cosa no supera en trascendencia la actividad desarrollada para producirla, y como estamos en supuestos en que la materia principal la ha aportado el cliente, no existe tampoco una obligación de dar la cosa resultante del hacer, pues siempre ha pertenecido a aquel. En rigor, lo que se advierte, una vez concluida la confección o fabricación, es la necesidad de entregar la cosa al cliente, entrega que en sentido puro puede ser calificada igualmente como un hecho, según se ha admitido en nuestro sistema jurídico ${ }^{43}$.

\footnotetext{
${ }^{41}$ Moreno Quesada plantea, como una de las clasificaciones posibles de las obligaciones de hacer, en este caso a partir de su objeto, aquella que distingue entre obligaciones "de puro hacer y relativas a cosas". Según explica el autor, en las primeras el actuar debido se agota en una conducta desconectada por completo de cualquier cosa o ente objetivo, y por lo tanto, la prestación no produce una modificación del mundo exterior sino a través de la recepción de dicha actividad por otros sujetos. En cambio, en las segundas -que expresa el autor son las más numerosas- el actuar del deudor hace referencia a una cosa, siendo ella a veces el resultado del hacer, cuando se trata de producir una cosa, y en ocasiones, con una existencia previa e independiente de la actividad del deudor, siendo una utilidad que a ella se refiere lo que la conecta con la prestación, como ocurre en los casos de transporte o custodia. El autor destaca que en este caso la cosa queda en un plano secundario, como una referencia pasiva. MORENO (1976), pp. 476-477.

${ }^{42}$ Sobre la prevalencia de la actividad por sobre las cosas en estos casos, Moreno Quesada expresa que "en las obligaciones de hacer el comportamiento prima sobre cualquier otra consideración: la realización de la conducta es lo que satisface el interés del acreedor". Moreno (1976), p. 469.

${ }^{43}$ Sobre el particular, por todos: PeñalliLlo (2011), pp. 190 y ss.
} 
A partir de lo expuesto, puede afirmarse entonces que la relación entre hacer y cosa no es óbice para que tales obligaciones entren en la noción de servicio, en tanto este supone un hacer o actividad que interesa o beneficia al cliente, $y$ puede indudablemente involucrar una cosa, sin que se altere la naturaleza de la prestación. Al respecto, si se miran además los textos europeos, se advierte que siendo el hacer o la actividad del deudor lo que destaca como contenido del servicio, no se excluye la presencia o incluso la producción de una cosa como consecuencia de aquella. Es más, si se observan las modalidades de contratos de servicios que se hacen objeto de regulación particular en dichos textos, se encuentran algunos que indudablemente incorporan la actuación del deudor sobre una cosa e, incluso, la creación de una cosa nueva. Es lo que sucede, por ejemplo, con el contrato de construcción, el de procesamiento y el de almacenamiento y depósito ${ }^{44}$. Visto así, los servicios pueden perfectamente configurarse como prestaciones de hacer que involucran o no una cosa material, sea como objeto -entendido como aquello sobre lo que se desplegará la actividad del deudor- o como resultado del hacer ${ }^{45}$.

Para concluir con el examen de los aspectos que caracterizan el servicio como prestación central en estos contratos, conviene hacer una breve referencia a la conexión del mismo con la clasificación que distingue entre obligaciones de medios y de resultado que, como es sabido, encuentra su origen en el derecho francés ${ }^{46}$. La razón de considerar este aspecto radica en que una de las principales cuestiones a que ha dado lugar el análisis del contrato de servicios,

\footnotetext{
${ }^{44}$ Así se aprecia en la regulación de dichos contratos, en el caso del DCFR, en los artículos IV.C. 3:101 y ss. (construcción); IV.C. 4:101 y ss. (procesamiento) y IV.C.5:101 y ss. (almacenamiento y depósito). Y en Ios PEL SC: arts. 2:101 y ss. (construcción); 3:101 y ss. (procesamiento) y 4:101 y ss. (almacenamiento).

${ }^{45}$ Como es lógico, lo aquí planteado no implica desconocer que es perfectamente posible también que en ciertos casos nos encontremos con relaciones contractuales que generen tanto prestaciones de dar como de hacer. Si fuere así, el escenario es diverso y será necesario definir si nos encontramos ante un único contrato de carácter mixto, o bien, ante dos contratos diversos. Es lo que ocurre, por ejemplo, con las ventas asociadas a servicios de instalación. Y es tal posibilidad lo que explica que los textos europeos de derecho uniforme reconozcan y fijen reglas aplicables a los supuestos de contratos mixtos, de servicios y alguna otra figura contractual (venta, donación, etc.) Así se observa en el artículo 1:101(3) de los PEL SC; y en el artículo II.1:107(2) del DCFR. En relación con esta misma cuestión se presenta lo referido a la naturaleza de los Ilamados contratos de suministro, o bien que envuelven un hacer con provisión de productos. Sobre tal delimitación: VilLanueva (2009a), pp. 67 y ss.

${ }^{46}$ Sobre la clasificación, su contenido y posibles alcances, entre otros: CABANILlas (1993); JORDANO (1991). En Chile, el profesor Peñailillo expresa que "se entiende por obligación de medio aquella cuya prestación consiste en el despliegue de una actividad del deudor dirigida a proporcionar cierto objeto, interés o resultado al acreedor. Se entiende por obligación de resultado aquella en la cual el deudor se obliga a proporcionar, en forma directa e inmediata, la satisfacción de un interés del acreedor, mediante la obtención de un resultado, el cual integra la prestación". Y agrega luego que en la primera "el resultado no está in obligatione", en tanto en la de resultado sí lo está. PeÑAilıLo (2011), pp. 223-224.
} 
especialmente en el derecho español, así como en los estudios referidos al modelo de contrato de servicios adoptado en el derecho uniforme europeo, ha sido precisamente la definición de si la obligación de prestar el servicio encaja exclusivamente en una u otra categoría, o si, por el contrario, según el caso concreto podrá ser calificada como de medios, o bien, como de resultado. En el derecho español, el desarrollo doctrinal y jurisprudencial ha llevado -a partir de la reglamentación del contrato de arrendamiento, al que se recurre por la falta de normativa particular sobre el contrato de servicios- a una distinción entre el denominado contrato de servicios y el contrato de obra, y desde allí a la afirmación habitual de que en el primero la obligación que nace para el prestador es de medios, mientras que en el segundo es de resultado, quedando estas últimas obligaciones excluidas del ámbito de los contratos de servicios en un sentido estricto ${ }^{47}$. En el caso del modelo de contrato de servicios del derecho uniforme, y particularmente en el DCFR, la regla del artículo IV.C 2:106 (1) conforme a la cual "el prestador de un servicio debe lograr el resultado indicado o previsto por el cliente en el momento de la celebración del contrato", ha planteado dudas y generado discusión acerca de si la obligación que surge para el prestador solamente puede ser una de resultado, excluyéndose la de medios ${ }^{48}$. Sin embargo, la controversia que inicialmente se suscitó por el tenor de la disposición aludida ha tendido a disminuir al ponerse de manifiesto y destacarse que en los comentarios oficiales al artículo respectivo -particularmente el Comentario $\mathrm{C}^{49}$ - se deja en claro que la regla es amplia y flexible, y por consiguiente, admite tanto servicios que dan lugar a un resultado como otros que generan obligaciones de medios. Así por lo demás queda en evidencia con el catálogo de contratos de servicios en particular que allí se regulan, y que comprenden figuras que generan una y otra clase de obligaciones.

Desde nuestro punto de vista, la mirada amplia es la más acertada: lo relevante es que la actividad desplegada por el prestador vaya en beneficio del cliente en los términos antes explicados, pudiendo o no comprometerse como parte de dicha actividad la consecución de un resultado. Esto dependerá de las

\footnotetext{
47 Sobre el particular: JiméneZ (2012), pp. 556 y ss. También Trigo (1999), pp. 173 y ss.

${ }^{48}$ Al respecto, entre otros: CRESPO (2013), pp. 5 y ss.; CRESPO (2015), pp. 93 y ss.; De BarRón (2008), pp. 13 y ss.

${ }^{49}$ Sobre el particular, el Comentario expresa: "The solution which is chosen in this Article reflects the idea that the probability that the result envisaged by the client can be achieved should be decisive for the obligation to be imposed upon the service provider [...] It is preferred to have a more flexible solution, which makes it possible to take into account the particularities of each type of service. Hence, if it is probable that the service can achieve the required result, an obligation to do so is imposed on the service provider (in the absence of a contractual provision to the contrary). If there is no such probability, the obligation is not imposed". Comentario C artículo IV.C.-2:106 DFCR.
} 
circunstancias concretas del contrato, que conducirán a definir si la obligación del prestador es de medios o de resultado en cada supuesto ${ }^{50}$. No hay razones de fondo para restringir el alcance del contrato a uno u otro tipo de obligaciones. Por lo demás, no obstante la falta de una regulación sistemática de esta categoría contractual en nuestro Código Civil, si consideramos todas las figuras contractuales que pueden coincidir con la idea de servicio aquí planteada, advertiremos que en ellas está presente una y otra clase de obligaciones. Basta mirar las normas del contrato de arrendamiento en sus modalidades conectadas con la noción de servicio y los ejemplos que allí se contienen, para comprobar que claramente envuelven obligaciones que a priori pueden encajar en ambos tipos de obligaciones. Ello sin perjuicio además de tener en cuenta que por la época de dictación de nuestro Código Civil -anterior al surgimiento de esta clasificación doctrinal- es difícil sustentar o encontrar reconocimiento de la misma en dicho cuerpo normativo en términos como los expuestos. Así las cosas, nos parece que no es posible recurrir a esta clasificación de las obligaciones a objeto de encontrar en ella una peculiaridad propia de los servicios, no obstante la distinción pueda aplicarse en los hechos a estos contratos.

En síntesis, y a partir del análisis de lo que constituye el servicio, podemos definir o delimitar la noción de los contratos de servicios como una categoría contractual generalmente onerosa que se caracteriza porque el prestador se obliga a ejecutar o realizar una actividad, sea material o inmaterial, que en sí misma considerada o junto con su resultado si lo hubiere, beneficia exclusivamente al cliente y satisface su interés, en tanto representa la utilidad que persigue concretar con su celebración.

Todo contrato que genere una obligación de estas características, puede ser calificado de servicios y debe quedar sujeto a las consecuencias jurídicas particulares de los mismos.

\section{Rasgos distintivos del contrato}

Habiéndose ya delimitado la noción de servicio y del contrato en que se inserta, nos centraremos en destacar las características propias de este último, las que resultan relevantes porque contribuirán en la construcción de su régimen jurídico, en tanto aportarán en la definición de ciertas consecuencias particulares derivadas de la pertenencia a esta categoría. Del amplio espectro de características que pueden predicarse de este contrato por el solo hecho

\footnotetext{
50 En nuestro país, María Sara Rodríguez ha expresado que si bien la mayoría de los contratos de servicios engendra obligaciones de resultado, ello no quiere decir que no puedan generar también obligaciones de medios, de modo que según su objeto, los servicios podrán ser de una u otra clase. RodríGuez (2014), p. 797.
} 
de ser tal, a nuestro juicio existen tres que conforman sus rasgos distintivos y que, por consiguiente, se verán reflejados en su disciplina: la prevalencia del interés del cliente; la especial trascendencia que en él revisten los deberes complementarios de conducta y el carácter generalmente oneroso que ostenta el contrato. A la explicación y justificación de los mismos nos abocaremos en las líneas que siguen.

\subsection{Contrato con un interés preponderante: el del cliente}

El contrato de servicios involucra, como indicáramos, un proceso colaborativo entre el prestador y el cliente, que se concreta y materializa en la ejecución de una obligación de hacer que necesariamente cede en beneficio e interés de este último, quien se encuentra protegido y amparado por el contrato.

Ese interés del cliente resulta prevalente en esta relación contractual, influyendo en diversos aspectos de su régimen jurídico. Por ello, a nuestro juicio estamos ante un rasgo distintivo del contrato de servicios, que se puede entender como una consecuencia de dos elementos presentes en el mismo y que se proyectan en su fisonomía. Primeramente, deriva de la circunstancia -ya puesta de relieve- de que el servicio está o debe estar orientado a hacerse cargo de las necesidades y requerimientos del cliente, es una actividad destinada a satisfacer sus exigencias ${ }^{51}$. Y, en segundo lugar, proviene de otro componente fundamental de este contrato, como es la confianza, entendida de una manera bien precisa, que pasamos a explicar.

Nos interesa precisar el sentido en que creemos debe ser entendida la confianza, puesto que si bien ha sido destacada por la doctrina como una característica de este contrato -especialmente a propósito del derecho a desistimiento que se reconoce en el mismo- no compartimos la forma en que ha sido abordada, pues nos parece confusa. En efecto, lo que se aprecia es que generalmente es identificada con el carácter intuitu personae que tendría el contrato, en razón del interés de las partes, en especial del cliente, y que fundaría el derecho a desistir de este último. Sin embargo, al mismo tiempo, y al examinar la procedencia de la indemnización de perjuicios resultante del ejercicio de tal derecho, se ha ubicado a los contratos intuitu personae como una especie dentro de los de confianza ${ }^{52}$. No se advierte con claridad

\footnotetext{
51 Al respecto: Loos (2011), pp. 763, 770, 778. De Barrón (2012), p. 1187. Del mismo modo se advierte en el concepto de servicio que los autores proporcionan en los comentarios a los PEL SC. Así se aprecia en los comentarios a los artículos 1:106 y 1:107. BARENDRECHT et al. (2007), pp. 202 y ss.

52 BetuChe (2015), pp. 69-126. La autora, al abordar el derecho de desistimiento, menciona la confianza como uno de sus fundamentos en los contratos de servicio de duración determinada y expresa -a propósito del modelo que proporciona el contrato de mandato- que "El intuitu personaeo confianza
} 
si estamos hablando de cuestiones idénticas o bien diversas pero en una relación género-especie.

En nuestra opinión, la confianza en este contrato alude algo bastante concreto: el cliente, cuando decide contratar, indudablemente tiene en consideración la experiencia del prestador del servicio y su profesionalismo o experticia en el área de que se trate. En definitiva, es en razón de sus habilidades y aptitudes personales, técnicas o materiales que opta por un prestador específico y no por otro. En esta dirección se ha afirmado, a propósito de los rasgos esenciales de este contrato, que el servicio se realiza en el desarrollo de una actividad profesional o empresarial que se sustenta en la confianza del cliente en la capacitación personal y material del prestador del servicio para realizar la tarea encomendada ${ }^{53}$. Siendo así, un contrato calificado de confianza claramente presenta un ámbito común con los contratos intuitu personae, y puede afirmarse que existe entre ellos una relación género-especie, mas es importante diferenciarlos, porque se trata de categorías que traen aparejadas consecuencias diversas ${ }^{54}$.

es su hilo conductor" (BeLUCHE (2015), p. 94), fundamento al que luego da un carácter general. Más adelante parece plantear una relación género-especie, al abordar las soluciones indemnizatorias tras su ejercicio, pues menciona como una causa más, que justifica el desistimiento sin indemnización, "la ruptura justificada de la relación de confianza en las relaciones de servicio intuitu personae" (BeluCHE (2015), p. 111 y 117). Más adelante parece plantear una relación género-especie, al abordar las soluciones indemnizatorias tras su ejercicio, pues menciona como una causa más, que justifica el desistimiento sin indemnización, "la ruptura justificada de la relación de confianza en las relaciones de servicio intuitu personae". BeluCHe (2015), p. 111. Y más adelante lo reitera BeLUCHe (2015), p. 117. Similar dirección se advierte en Gálvez (2008), pp. 15 y ss.; y pp. 42-47. El autor, centrándose en los servicios profesionales, asimila las nociones de contrato de confianza e intuitu personae; tratándose de los otros contratos de servicios, no cree que pueda darse una solución concluyente de si es una característica propia del contrato. Asimismo, reconoce que en la doctrina general los conceptos intuitu personae, fiducia e infungibilidad suelen emplearse de forma indistinta para designar el carácter marcadamente personal de algunas obligaciones o contratos.

53 De Barrón (2012), p. 1140.

${ }^{54}$ Entre nosotros esta terminología usualmente se emplea en el contrato de mandato y en el de sociedad, en los que la confianza aparece como un elemento de la esencia, resaltándose el carácter intuitu personae para efectos de justificar algunas causales especiales de terminación, tales como la muerte, la revocación o la renuncia, mas no se precisan estas nociones. Así se observa en StITCHKIN (2009), pp. 39-40. El autor luego precisa que una consecuencia del carácter de confianza del mandato es que es un contrato intuitu personae STITCHKIN (2009), p. 163. Por su parte, Meza, si bien al tratar el mandato se refiere solo al carácter de confianza, aplica consecuencias propias de los intuitu personae, por ejemplo, el error. Meza (2010), p. 171. Mas a propósito del contrato de sociedad, identifica los términos. MEZA (2010), p. 150. 
La confianza, como género ${ }^{55}$, implica que el prestador es responsable ante el cliente por la correcta ejecución del servicio encomendado, sea que lo ejecute él mismo o lo haga a través de un tercero. Mientras que el carácter intuitu personae, como especie particular, hace referencia a aquellos contratos que se celebran exclusivamente en atención a la persona del otro co-contratante, por las cualidades especiales que él detenta, personales o profesionales ${ }^{56}$. En este sentido, como ha sostenido nuestra doctrina, en tal caso la persona es un elemento esencial en el contrato ${ }^{57}$, de manera que la obligación de hacer dimanante del mismo conlleva a la prestación de un servicio no fungible, es decir, que solo podrá realizar ese deudor ${ }^{58}$. Así, a modo de ejemplo, un contrato de servicios médicos acordado con un profesional específico -un cardiólogo de especial prestigio- será usualmente un contrato de confianza e intuitu personae; mientras que el contrato de servicios de asesoría contable que presta una empresa a sus clientes, usualmente será sólo un contrato de confianza.

La importancia del distingo formulado se proyecta, en especial, en la figura de la delegación y, por ende, en la forma de cumplimiento del contrato ${ }^{59}$, en tanto aquella no será admisible si el contrato de servicios es, además, intuitu personae. La posibilidad de delegar o encargar todo o parte de la ejecución del servicio a uno o varios terceros goza de asiento normativo en nuestro derecho en las reglas contenidas en el contrato de mandato, en el que la delegación es un elemento de la naturaleza, lo que se justifica porque el mandatario siempre queda responsable frente al mandante de los actos del delegado, sea que aquel haya autorizado o no la delegación (artículo 2135). Así, si existe delegación, se posibilita la realización de la prestación directamente por el prestador del

\footnotetext{
${ }^{55}$ Villanueva (2009 a), pp. 218-219. En contra Gálvez Criado, quien entiende que el género viene constituido por las obligaciones intuitu personae. Sin embargo, hace presente que lo propio de los negocios fiduciarios es la peculiar relación jurídica que existe entre los contratantes, cuyo carácter se predica de todo el contrato y no de particulares obligaciones nacidas del contrato, como acontece con las obligaciones de hacer que son las que pueden calificarse de intuitu personae. Gálvez (2008), pp. 16-23.

${ }^{56}$ Así: Moreno (1976), p. 473; Alessandri et al. (2011), p. 212.

57 Por todos, Peñailillo, quien afirma que en tales casos la persona integra la prestación. Peñalıııo (2011), p. 191.

${ }^{58}$ Gálvez (2008), pp. 16-17.

59 Esta posibilidad se conecta con la clasificación de las obligaciones de hacer en fungibles y no fungibles, abordada por MORENO (1976), p. 470. A propósito en particular de los contratos de servicios, Villanueva afirma que el carácter intuitu personae no puede presumirse y por esto, por regla general, el deudor en el cumplimiento puede servirse de un tercero, respondiendo de su actuación frente al acreedor. VILLANUEVA (2009b), pp. 121-122. En sentido similar y como un carácter del contrato y no de la obligación, Gálvez (2008), pp. 16-7. Conectando el carácter fungible o infungible de la obligación con la posibilidad de delegar en los contratos de servicios: RodríGuez (2014), p. 796.
} 
servicio, o bien, a través del auxilio de otras personas, mas como subsiste el elemento de la confianza, el primero siempre será responsable frente al cliente de las actuaciones de dichos terceros, y sin necesidad de una estipulación expresa en tal sentido. Si el contrato además tiene carácter intuitu personae, esta posibilidad de ejecución por terceros debe descartarse, y si de hecho tuviera lugar, estaríamos ante un incumplimiento contractual del prestador.

Otra relevante proyección de este distingo entre confianza y carácter intuito personae lo advertimos en los supuestos de imposibilidad sobrevenida subjetiva en relación con el prestador, porque si el contrato de servicios se califica de intuitu personae, la ejecución del servicio por parte de un tercero no permitiría obtener la satisfacción del interés del acreedor ${ }^{60} y$, por consiguiente, se configuraría un supuesto de imposibilidad extintiva de la obligación que no se dará si el contrato se mantiene solamente en el género de la confianza.

En cambio, creemos que la diferenciación planteada no tiene trascendencia, a pesar de que así lo ha planteado la doctrina nacional, en materia de remedios frente al incumplimiento, y más concretamente, en lo referido a la pretensión de cumplimiento. Ello, porque si bien tradicionalmente se ha afirmado que en los contratos que se califican de intuitu personae no es posible la ejecución "in natura" que efectúa un tercero a costa del deudor -ex art. 1553 del Código civil $^{61}$-, lo cierto es que en los contratos de servicios en general, atendido que su objeto lo constituye una obligación de hacer, pretender forzar al deudor a cumplir es una alternativa que se considera está en abierta contradicción con su libertad individual ${ }^{62}$, y ello sin perjuicio de su carácter de confianza o intuito personae.

Finalmente, es preciso volver sobre el rasgo distintivo que nos ocupa, y su influjo en el contrato. Hemos dicho que en este se observa un interés prevalente: el del cliente, y que dicha peculiaridad se expresa en el régimen del

\footnotetext{
60 Villanueva (2009 b), pp. 141-144.

61 En la doctrina nacional por todos: Abeliuk (2010), p. 373.

${ }^{62}$ En el escenario descrito cabe preguntarse si la pretensión de cumplimiento sigue formando parte del catálogo de remedios en caso de incumplimiento de un contrato de servicios. Creemos que si bien su rol es más reducido no debe descartarse de plano su procedencia. Así por ejemplo, podría reconocerse al prestador del servicio la posibilidad de subsanar su cumplimiento mediante la reparación o sustitución de la prestación defectuosa, modalidades de este remedio. Esta alternativa está expresamente recogida en los textos que conforman el nuevo derecho de la contratación, sin perjuicio de que se prevén una serie de limitaciones que pueden incidir directamente en su procedencia. Y no obstante, desde una perspectiva práctica, puede ocurrir que el cliente descarte este remedio porque ha perdido la confianza en su prestador. Piénsese, por ejemplo, en un contrato cuyo servicio contratado es la remodelación y construcción de parte de una vivienda que ha sido ejecutado de forma defectuosa. No será tan sencillo para ese cliente insistir en la reparación por dicho prestador. En esta ocasión nos limitamos en dejar planteada la cuestión, cuyo análisis será objeto de otro trabajo.
} 
contrato. La principal manifestación de la misma la encontramos a propósito del desistimiento. Éste, como una forma de poner término de manera unilateral al vínculo jurídico obligatorio, ha sido entendido como connatural a este contrato, y podemos afirmar que ello encuentra su fundamento en esta característica. Es la especial trascendencia que se confiere al cliente y su interés lo que justifica el reconocimiento de este derecho a su favor y que le permite salir legítimamente del contrato.

Diferimos por tanto de aquella doctrina que considera que es la pérdida de confianza el verdadero fundamento de esta facultad ${ }^{63}$, sin perjuicio de que si ello acontece pueda dar lugar a un desistimiento causado, que a su vez incida en la extensión de la indemnización que se asocia comúnmente al ejercicio de este derecho ${ }^{64}$. Ahora bien, para efectos de determinar el real contenido y alcance del desistimiento en los contratos de servicios, debe necesariamente ser considerado el remedio resolutorio (artículo 1489 del Código Civil) porque estamos en presencia de un contrato bilateral, de modo que su ejercicio podría confundirse desde una perspectiva práctica y/o jurídica, con una forma de resolución unilateral, abriéndose paso a una opción que modifica la forma en que tradicionalmente se ha entendido opera la resolución en nuestro ordenamiento jurídico, es decir, mediante sentencia judicial. Resultará, por tanto, relevante zanjar una serie de cuestiones: si la resolución y el desistimiento son mecanismos concurrentes; si el desistimiento puede encubrir una resolución unilateral cuyo ejercicio queda entregado a la libertad del cliente, o bien, si se trata de derechos excluyentes, así como sus efectos e incidencia en la extensión de una posible indemnización de perjuicios. Problemas que en esta oportunidad no podemos abordar y que dejamos simplemente esbozados, pero en cuya solución deben necesariamente incidir las categorías de las que forma parte el contrato de servicios.

\subsection{Contrato con especial incidencia de los deberes complementarios a la prestación central}

Una segunda característica relevante de esta categoría contractual es la trascendencia que cobran ciertas conductas diversas y adicionales a las prestaciones centrales de cada parte -el servicio y el precio- y cuya función es complementarlas a efectos de que se alcancen los fines perseguidos por

\footnotetext{
${ }^{63}$ Villanueva (2009b), p. 151, refiriéndose a los contratos de duración determinada.

${ }^{64}$ Para efectos del desistimiento, cuando se conecta con la existencia de causa, ello va más allá del incumplimiento contractual. Así, se ha sostenido que "es aquella circunstancia sobrevenida que impide exigir a la parte afectada que continúe vinculada contractualmente, teniendo en cuenta las circunstancias del caso concreto y una vez sopesados los contrapuestos intereses de las partes". KLeIN (1997), p. 60.
} 
los contratantes. Si todo contrato contiene una regla de conducta ${ }^{65}$ que se construye a partir de la declaración de voluntad de las partes, debidamente interpretada e integrada, es posible advertir que aquella es de carácter complejo, puesto que no solamente pone a los contratantes en la necesidad de ejecutar las prestaciones primarias o características del contrato, sino que también les impone la realización de otras conductas diferenciadas, en función de permitir la plena satisfacción del interés que perseguían al celebrarlo.

En el caso del contrato de servicios, lo anterior es particularmente marcado toda vez que hemos dicho ya que el mismo regularmente se desarrolla como un proceso dinámico, a lo largo del cual es natural y recurrente advertir una serie de comportamientos vinculados con la entrega de informaciones recíprocas, instrucciones, posibles supervigilancias, etc., que son exigibles entre el prestador y el cliente. En el curso de dicho proceso, acompañan al servicio una serie de conductas que permiten la comprensión del contenido del contrato en su integridad.

Como es lógico, la incorporación de estos comportamientos en la relación jurídica obligatoria de servicios resulta plenamente justificada a partir del tenor del artículo 1546 del Código Civil, que consagra la buena fe objetiva, y que permite completar la regla contractual ${ }^{66}$. Ahora bien, el desafío que plantea este rasgo distintivo del contrato en estudio es desarrollar y dotar de contenido estas conductas complementarias. Ello es necesario atendido que, como se ha expresado en doctrina, si bien desde un punto de vista técnico la remisión a la buena fe puede ser efectiva para fundamentar o sustentar su exigibilidad en el contrato, no basta para articular sistemas más complejos como son los que se generan al interior de este contrato ${ }^{67}$. La necesidad de insertar estas exigencias en el contexto y régimen general del contrato de servicios, justifica la necesidad de abordarlas y estudiarlas, de modo de perfilar adecuadamente su alcance y trascendencia.

La doctrina que ha examinado estos comportamientos -tanto en general en los contratos, como en particular en los de servicios- emplea indistintamente

${ }^{65}$ Díez-Picazo (2007), pp. 424 y ss. El autor expresa: "el contenido de todo contrato se reduce, pues, a una o varias reglas de conducta".

${ }^{66}$ Sobre la construcción de la regla contractual en general, y en particular en nuestro sistema jurídico: VIDAL (2000), pp. 209-227.

${ }^{67}$ Así lo expresa Ferrer, defendiendo la idea de que en caso de asumirse la regulación legal de los contratos de servicios, debe propenderse a plasmar normativamente los deberes de cooperación que surgen en ellos. Ferrer (2012), p. 5. 
los términos obligación, deber y carga ${ }^{68}$ para referirse a ellos. Y esto es relevante porque no se trata solamente de una cuestión de nomenclatura, sino que, en rigor, dice relación con su naturaleza jurídica y, por consiguiente, con las consecuencias que traen aparejadas, particularmente en caso de inobservancia. En atención a ello, nos parece relevante para evitar confusiones, precisar el significado de tales denominaciones.

La mayoría de la doctrina nacional distingue el deber jurídico de la obligación en atención a las consecuencias que trae aparejado su cumplimiento o incumplimiento. Siendo ambos imperativos de conducta, la particularidad del deber radica en que conlleva la imposición o abstención de una determinada conducta necesaria para el correcto desenvolvimiento del contrato, pero que, sin embargo, no es susceptible de ejecución forzada. Ello, a diferencia de la obligación que presupone un vínculo jurídico entre personas determinadas que impone la ejecución de una prestación, sea de dar, hacer o no hacer, cuyo incumplimiento habilita al acreedor para valerse de los diversos remedios frente al mismo, incluida la ejecución en naturaleza de la prestación. En ella, a diferencia del deber, se da una necesaria correlatividad con un derecho personal, que explica la facultad del acreedor de reclamar o exigir su cumplimiento tal como fue concebida al celebrarse el contrato $^{69}$. Ahora bien, no obstante la diferencia derivada de poder reclamarse o no el cumplimiento en naturaleza de la conducta impuesta en uno y otro caso, la infracción tanto de las obligaciones como de los deberes puede ser calificada como un incumplimiento contractual ${ }^{70}$.

\footnotetext{
68 Así, por ejemplo, Escartín afirma que los deberes de colaboración entre los contratantes conllevan obligaciones o cargas, quedando en evidencia el uso indistinto de los términos. Escartín (2012), p. 12. Ello, sin perjuicio de que igualmente se hace presente que pueden compartir más de uno de estos caracteres, como acontece con la regulación que proporcionan el DCFR y los PEL SC al deber de colaboración, que en algunos supuestos es tratado jurídicamente una obligación, en atención a las consecuencias que trae aparejado su incumplimiento en tanto confiere el derecho a demandar una indemnización de perjuicios, mientras que, en otros supuestos, parece ser considerado únicamente como carga. Así, hablan de deberes para el caso de la cooperación en el DFCR: EIDENMüLler et al. (2009), p. 1488. También para la cooperación, pone de manifiesto la falta de claridad sobre su naturaleza De Barrón (2008), pp. 19 y ss. Por su parte, Villanueva habla de obligaciones principales, complementarias, accesorias y deberes de protección o conducta en la prestación de servicios, para referirse a la obligación de seguridad, de conservar, de información, instrucción y consejo. ViLLANUEVA (2009 a), pp. 397 y ss.

En un sentido más amplio con relación al deber y la obligación, aunque emplea con relación a estos la expresión carga. Fuertes-Planas (2008), pp. 65 y ss.

${ }^{69}$ Como expresa Peñailillo: "existiendo un derecho, existe una obligación y viceversa; si hay un obligado es porque hay un titular que puede exigir esa obligación y viceversa". Peñallitlo (2011), p. 27. En sentido similar: DíEz-PICAZO (2008), p. 71.

70 Díez-Picazo afirma que en el primer caso hay un incumplimiento en sentido técnico y en el segundo un cumplimiento defectuoso. DíEz-PICAZO (2008), p. 145.
} 
El término carga, por su parte, es de origen procesal y trasladado al derecho privado, alude a la imposición legal o convencional, de una determinada conducta con la finalidad de evitar una consecuencia jurídica desfavorable, cuyo incumplimiento acarrea para su titular desventajas jurídicas, efectos desfavorables para sus intereses ${ }^{71}$.

Conforme a lo señalado, la distinción formulada radica en el fin al que tienden una y otra conducta, esto es, a su función en el contrato: mientras los deberes -al igual que las obligaciones- se encaminan o consideran la protección del interés del co-contratante; las cargas miran exclusivamente al interés de aquel llamado a observarlas ${ }^{72}$.

Si bien los fines de este trabajo no permiten profundizar en esta cuestión, cabe señalar que a nuestro juicio, las conductas adicionales a las prestaciones centrales de los contratos de servicios se ubican más bien en el terreno de las obligaciones o de los deberes jurídicos, de modo tal que su inobservancia incide directamente en los remedios frente al incumplimiento, en especial en la indemnización de perjuicios. Y ello puede advertirse con una breve revisión de dos frecuentes exigencias de conducta en los mismos, como son la colaboración y la información.

Tratándose de la colaboración, estamos ante un imperativo característico de este contrato, sin perjuicio de que su intensidad pueda variar dependiendo del servicio concreto sobre el que verse. Por lo mismo, es un comportamiento que puede adoptar diversas concreciones que se proyectan a lo largo de toda la ejecución del contrato. En efecto, el servicio, concebido como un proceso dinámico, puede sufrir en su desarrollo alteraciones que incidan en la definición del objeto del contrato, por lo que no es infrecuente-como lo destacamos previamente- que las partes al celebrar el contrato prevean o contemplen el servicio en términos generales, incluso esto puede ocurrir así por su propia naturaleza, de manera que sus especificaciones solo se logran mediante el despliegue de esta conducta de colaboración. En este contexto, las instrucciones del cliente al prestador del servicio permiten perfilar el contenido del contrato, sin perjuicio del grado de autonomía que tenga éste en su ámbito propio de

\footnotetext{
${ }^{71}$ Peñailillo la define como: "la necesidad de adoptar alguna conducta si se quiere lograr cierto resultado" Peñailitlo (2011), p. 80. Por su parte, Badosa la entiende como: "una conducta que se debe realizar solamente si se pretende evitar las consecuencias negativas que comportaría su no observancia". BADOSA (1987), p. 317.

72 Así, se ha expresado: "la obligación es un sacrificio en interés ajeno; la carga, en uno propio" AlESSANDRI et al. (2011), p. 11. Tal afirmación es perfectamente aplicable a la distinción deber-carga.
} 
actuación, en función de su profesión u oficio ${ }^{73}$. En esta línea se inserta también lo señalado previamente en orden a que -por el interés en que se desarrolla el servicio, el del cliente- se pueden generar modificaciones al objeto inicial del servicio cuando esté sujeto a elecciones que las partes, particularmente el cliente, deben tomar a posteriori y que pertenecen a la colaboración necesaria en este contrato ${ }^{74}$.

Una de las principales manifestaciones de la colaboración lo constituye sin duda aquel comportamiento que el acreedor -normalmente el cliente- debe desplegar a efectos de favorecer o permitir la ejecución de la prestación del deudor. Así, por ejemplo, si en un contrato de construcción se requieren previamente de permisos municipales que debe tramitar el propietario, o resulta indispensable que se le permita al prestador acceder al lugar donde materialmente trabajará, hay una conducta de colaboración exigible al acreedor del servicio, como se ha fallado por nuestros tribunales ${ }^{75}$. Se trata de un comportamiento que resulta indispensable para que el servicio pueda concretarse debidamente y se alcancen a cabalidad los fines perseguidos con el contrato. Si, como hemos destacado, el servicio consiste en un hacer cuya configuración comúnmente se realiza en función de las necesidades y requerimientos del cliente, la participación activa de éste será fundamental para que pueda ejecutarse adecuadamente, lo que justifica la trascendencia de este deber en esta clase de contratos.

En sus diversas manifestaciones, la colaboración se proyecta con una función tal en el contrato que la falta de la misma no puede sino identificarse como un incumplimiento contractual, de modo tal que estaremos en el terreno

\footnotetext{
73 En este sentido, Ferrer (2012), pp. 2-3 y 6-7. Cabe precisar que el DFCR prevé la obligación general de colaboración en el art. IV.C.2:103 y como una particularización del mismo, las indicaciones del cliente en el art. IV.C.2:107.

${ }^{74}$ Así, por ejemplo, se puede extraer del artículo IV. C 2:109 del DFCR.

75 La Corte Suprema ha considerado esta cuestión en un caso en que habiéndose encargado la construcción de una obra, el cliente durante el curso del contrato impide el ingreso del prestador al terreno en que se estaba desarrollando la misma. Si bien no habla de colaboración o cooperación, sí concluye que el propietario incumplió su obligación contractual tácita de posibilitar la normal ejecución de la obra encargada. Sentencia Corte Suprema, rol No 6859-2007, de 9 de marzo de 2009. Algo similar ocurrió en la sentencia de la Corte de Apelaciones de Valparaíso, confirmado por la Corte Suprema, en que en un contrato de obra (reparaciones y adaptaciones de un local para funcionar como pizzería) se resolvió que quien había encargado la obra y demandaba la resolución del contrato, había incurrido en un incumplimiento del contrato al impedir al prestador el acceso al recinto en que se desarrollaban los trabajo. En concreto, la Corte de Apelaciones expresa: "[...] lo cierto es que el actor, por su parte, al impedir que éste cumpliera lo encomendado cuando se encontraba llano a ello, ha incumplido a su vez el contrato que supone dar para el contratista las facilidades para realizar su labor, de manera que el demandado no se encuentra en mora de cumplir sus obligaciones [...]". Sentencia Corte Suprema, rol No 2459-2008, de 13 de agosto de 2009.
} 
de, al menos, deberes contractuales, sin perjuicio de que el contenido de la conducta exigida tenga tal grado de autonomía que pueda configurarse como una obligación que admita incluso el remedio del cumplimiento en naturale$\mathrm{za}^{76}$. Si no alcanza tal entidad, al menos podemos plantear que su infracción es susceptible de generar otros efectos propios del incumplimiento contractual ${ }^{77}$, por ejemplo, la indemnización de daños. Descartamos que podamos quedarnos simplemente en la calificación de carga, que importante doctrina le ha dado ${ }^{78}$, atendido que no se trata de imperativos exigidos solamente en interés de sus destinatarios.

Con relación a la información ocurre algo similar ${ }^{79}$. Múltiples son sus manifestaciones incluso desde la fase precontractual, debiendo el prestador del servicio proporcionar toda la información que resulte indispensable para que el cliente pueda cerciorarse sobre si el servicio ofertado puede realmente satisfacer su interés contractual y, al mismo tiempo, pesando sobre el cliente la exigencia de entregar la información necesaria para que el prestador pueda asumir seriamente la realización del mismo. Esta información debe revestir caracteres mínimos, que usualmente la doctrina ya ha desarrollado principalmente en materia de consumo: veraz, comprensible y de contenido suficiente ${ }^{80}$. En la fase de cumplimiento del contrato se manifiesta, por ejemplo, dar a conocer las vicisitudes del servicio presentes en su ejecución ${ }^{81}$. Teniendo a la vista el DCFR, la información se manifiesta también en cargas de advertencia para evitar que el contrato se celebre sobre bases erróneas que incidan luego en la insatisfacción del interés del cliente, tales como que el servicio podrá obtenerse a un precio mayor o que existirá una demora en su obtención ${ }^{82}$. En nuestro ordenamiento será fundamental determinar hasta donde se extiende esta exigencia de conducta, teniendo en consideración la diligencia que resulta exigible a las partes, y la

\footnotetext{
76 DíEz-Picazo (2008), pp. 144-146.

77 No obstante, las dudas sobre la naturaleza de la colaboración en el derecho uniforme europeo, hay en sus textos base para sostener que la inobservancia de la misma conduciría a los remedios por incumplimiento. Así lo expresa Loos, aludiendo expresamente a la posibilidad de recurrir a la resolución si el incumplimiento es esencial, Loos (2011), p. 775.

78 Por todos: Vaquer (2011), pp. 155 y ss.; Díez-Picazo (2008), p. 136. Entre los autores nacionales, al menos en ciertos supuestos la considera carga: SAN MARTín (2009), p. 195.

${ }^{79}$ De hecho, se puede ver en la información una especial manifestación de la cooperación entre las partes.

80 Ferrer (2012), pp. 3-4; Schulze (2006), pp. 36-38; De Barrón (2008), pp. 7-9.

81 De BARRÓN (2008), p. 11.

${ }^{82}$ Así se advierte en las reglas generales, en los artículos IV.C. 2:102 y 2:108; y en las especiales, a propósito del contrato de diseño, en el artículo IV.C. 6:102.
} 
asimetría o no que puedan tener en la información, en atención al carácter de especialistas que el cliente o prestador del servicio puedan tener ${ }^{83}$.

A nuestro juicio, en estos casos también parece ser que la calificación más adecuada, en vistas a definir sus consecuencias en el contrato, es la de un deber complementario y, eventualmente, una obligación. Su omisión o infracción, genera indudablemente un incumplimiento contractual que incide en la concreción de los intereses de ambos contratantes, de modo tal que, a partir de su función en el contexto íntegro del contrato, habrá de definirse su naturaleza jurídica y los efectos derivados de su inobservancia.

Lo expresado corresponde a ciertas ideas iniciales sobre esta materia, para dar cuenta de cómo la presencia de estas conductas -que por supuesto van más allá de la colaboración e información que aquí hemos considerado a efectos ilustrativos- constituye un rasgo distintivo del contrato; pero permite advertir que es preciso avanzar en su desarrollo y estudio, como parte fundamental de la conformación de la disciplina de esta categoría contractual.

\subsection{Es un contrato generalmente oneroso}

El contrato de servicios es un contrato que generalmente reporta utilidad a ambas partes y que, además, es bilateral de conformidad a los criterios que proporcionan los artículos 1440 y 1439 del Código Civil, respectivamente.

Usualmente su carácter oneroso descansa en la remuneración, que es considerada por la doctrina un elemento de la naturaleza del contrato y, por lo mismo, se pone énfasis en que no cambia su calificación jurídica en el supuesto de contratos gratuitos ${ }^{84}$. La utilidad y, por ende, la remuneración, se manifiestan usualmente en un precio que se pagará en dinero a cambio de una actividad, al que el prestador del servicio puede, en todo caso, renunciar.

La justificación de esta característica descansa en que se considera que los servicios suelen ser prestados por expertos ${ }^{85}$. Por tratarse la remuneración de un elemento de la naturaleza, si las partes nada han dicho sobre el particular,

\footnotetext{
${ }^{83}$ A propósito de la regulación que ofrece el DCFR, De Barrón destaca a propósito de la colaboración e información que "la igualdad en cuanto a derechos y obligaciones de las partes contractuales puede considerarse como uno de los elementos definitorios del negocio jurídico". De Barrón (2008), p. 7.

${ }^{84}$ Villanueva (2009a), p. 187. En esta dirección va también el artículo IV.C. 1:101 (1) (b) del DFCR y el 1:102 de los PEL SC. Severin, refiriéndose al rol del precio en el contrato expresa: "puede entenderse que el carácter gratuito de la prestación que asume el prestador del servicio no alcanza a excluir la estructura típica del contrato". Severin (2014), p. 245.

${ }^{85}$ Villanueva expresa que "la profesionalidad del prestador del servicio es un indicio de la onerosidad de la prestación". Villanueva (2009 a), pp. 187 y ss. En este sentido, el art. IV.C. 2:101 del DCFR dispone que si el prestador del servicio es un empresario o profesional el contrato se presume oneroso, salvo indicación en contrario. En línea similar, los PEL SC disponen en el artículo 1:102 (1).
} 
el contrato debe considerarse remunerado. En este contexto cabe preguntarse ¿qué acontece si las partes no han fijado una remuneración? Esto puede suceder, por ejemplo, porque en algunos casos no es posible determinar el precio antes de perfeccionar contrato e incluso ejecutar el servicio (piénsese en el prestador que debe reparar un aparato electrónico y no sabe, al iniciar la prestación, cuál es el desperfecto preciso de que adolece y lo que será necesario para subsanarlo). Para efectos de su determinación, para fijar su monto supletoriamente, la solución nos parece la encontramos en aquella regla que nuestro legislador civil reitera en los contratos que pueden calificarse de servicios: considerar los usos del tráfico o el precio de mercado al tiempo de la celebración del contrato $^{86}$. Por otra parte, si bien la remuneración consistirá en dinero, nada obsta que su pago pueda realizarse a través de otra prestación que sea equivalente al monto de aquella.

Las partes podrán estipular que la prestación del servicio sea gratuita. Nada les impide suprimir la remuneración del contrato de servicios y esto puede obedecer a razones de diversa índole: amistad, cortesía o simple benevolencia o voluntariado. Lo anterior no altera la naturaleza del contrato de servicios que-como abordáramos- se caracteriza fundamentalmente por una prestación de hacer. Tampoco, por cierto, ve alterado su carácter de bilateral porque la reciprocidad e interdependencia de estos contratos, a nuestro juicio, radica en la serie de conductas que las partes deben desplegar para la obtención del servicio y que, en el caso del cliente, no se limitan al pago del precio, sino que también le impone colaborar en el proceso que involucra el servicio para que el contrato pueda ser cumplido. Por las consideraciones expuestas, adherimos a la doctrina que niega que sea posible entender que, tratándose de servicios gratuitos, realmente se configure una donación por parte del prestador del servicio, principalmente porque la donación se caracteriza por constituir un título translaticio de dominio, que origina una obligación de dar y no de hacer, y además constituye un contrato unilateral, ambos elementos que claramente difieren de los contratos de servicios ${ }^{87}$.

Distinguir si la prestación de servicios es gratuita u onerosa, incide, a nuestro juicio, en el remedio de la indemnización de perjuicios. Por una parte, de manera indirecta influye en su procedencia, en lo referido a la apreciación del

\footnotetext{
${ }^{86}$ En tal sentido, el artículo 2117 inciso segundo del Código Civil (en el mandato) y el artículo 1997 del Código Civil (en los contratos para la confección de una obra material, aplicable también al arrendamiento de servicios inmateriales, por la remisión del artículo 2006). Los PEL SC fijan como regla supletoria la del "market price generally charged at time of the conclusion of the contract" (artículo 1:102 (2)).

${ }^{87}$ Así se expresan VilLANUeVA (2009a), p. 192 y Severin, quien afirma, refiriéndose a los contratos de servicios gratuitos en el DFCR: "un contrato de servicio gratuito no se considera, ni se regula, como una especie de donación". SEverin (2014), pp. 240-245.
} 
elemento de la reprochabilidad, concretamente el grado de culpa de que responde el deudor, de conformidad al artículo 1547 del Código Civil ${ }^{88}$. Ello, tanto si se demanda en forma autónoma o en conjunto con otro remedio. Asimismo, en los supuestos de terminación del contrato por desistimiento, nos parece que el carácter oneroso tendrá incidencia para determinar su extensión ${ }^{89}$.

Se han planteado también otras consecuencias del carácter oneroso que generalmente ostenta el contrato ${ }^{90}$, pero nos parece que son estas las que deben ser destacadas por constituir las que indudablemente se asocian al mismo.

\section{Conclusiones}

1. El carácter atípico del contrato de servicios, no obstante su innegable trascendencia en el tráfico jurídico, así como la insuficiencia, por si solos, de los regímenes particulares de los contratos que en el Código Civil se conectan con la idea de servicio, hace necesario abordar la tarea de perfilar su noción como categoría contractual general y sus características, de modo de contribuir a la construcción de su régimen jurídico.

2. La configuración de su régimen jurídico se concreta a partir de diversas disposiciones generales y especiales contenidas en nuestro Código Civil, y que

\footnotetext{
${ }^{88}$ Descartamos que pueda tener relevancia cuestionarse la procedencia de las obligaciones de garantía (saneamiento de evicción y vicios ocultos), que constituyen otras de las consecuencias clásicas del carácter oneroso de un contrato. No proyectamos en dicho terreno esta característica del contrato por dos razones que están vinculadas: por una parte, se trata de obligaciones cuyo origen, desarrollo y contenido se explican en la estructura de una obligación de dar y no de hacer; y, por otra, a partir de la noción amplia y objetiva de incumplimiento que emplea la doctrina civil actual, a la que adherimos. Sus supuestos de procedencia pueden quedar subsumidos en dicha noción general, independientemente de que el contrato sea oneroso o no.

${ }^{89}$ Son elementos que considera parte de la doctrina. En este sentido Villanueva, aunque no compartimos todas sus conclusiones, VilLanUeVA (2009b), pp. 155-159. Si el contrato de servicios es oneroso, nos parece que por la naturaleza del remedio de la resolución, comparado con el desistimiento, la extensión de la indemnización no podría ser equivalente. A nuestro juicio, habrá que tener en cuenta también el carácter conmutativo que usualmente tendrá el contrato, por la relevancia de los resultados económicos que las partes habrán anticipado y evaluado como equivalentes.

${ }^{90}$ Es lo que ocurre, por ejemplo, con los remedios sinalagmáticos, básicamente la resolución y la excepción de contrato no cumplido, en tanto se ha negado su procedencia en aquellos contratos de servicios de carácter gratuito. Así lo expresa Severin (2014), p. 248, aunque no profundiza en la razones de la exclusión. Sin embargo, creemos que esto no es preciso. La procedencia de estos remedios viene determinado por su presupuesto propio, en el primer caso, al configurarse un incumplimiento resolutorio y, en el segundo, la existencia de un incumplimiento que impedirá al deudor que ha incurrido en él, exigir el cumplimiento de la contraprestación mientras no esté dispuesto a ejecutar la propia. Adicionalmente, como hemos señalado antes, la ausencia de precio o remuneración no convierte al contrato de servicios en unilateral, razón que podría estar detrás de este planteamiento. Una referencia a las consecuencias de distinguir entre servicios gratuitos y retribuidos realiza. VILLANUEVA (2009a), pp. 192-193.
} 
reflejan los elementos comunes de esta categoría contractual que permiten concebirla en términos amplios y flexibles, a pesar de la diversidad que en la práctica presenta.

3. El análisis de esos aspectos comunes en relación con la noción de servicio, muestra que estamos ante contratos en que destaca como objeto una obligación de hacer, cuya prestación consiste en ejecutar o realizar una actividad, sea material o inmaterial, que en sí misma considerada o junto con su resultado si lo hubiere, beneficia exclusivamente al cliente y satisface su interés, en tanto representa la utilidad que persigue concretar con el contrato. Esta actividad es lo que constituye el servicio. Todo contrato que tenga este objeto podrá ser calificado como de servicios.

4. Este contrato presenta ciertos rasgos característicos que deben ser considerados: la preponderancia del interés del cliente por sobre el del prestador del servicio; la especial importancia que revisten los llamados deberes complementarios de conducta que rodean o apoyan las prestaciones centrales de las partes; y su natural onerosidad. Estas características se proyectan en su régimen $y$, por consiguiente, deben guiar las soluciones a las problemáticas que esta categoría contractual presenta.

\section{BiBLIOGRAFÍA CITADA}

Abeliuk Manasevich, René (2010): Las Obligaciones, Reimpresión 5a edición (Santiago, Editorial Jurídica de Chile), Tomo I.

Alessandri Rodríguez, Arturo; Somarriva Undurraga, Manuel y Vodanovic HaKııCKA, Antonio (2011): Tratado de Derecho Civil. Parte Preliminar y Parte General (Santiago, Editorial Jurídica de Chile), Tomo II.

BADOSA ColL, Ferrán (1987): La diligencia y la culpa del deudor en la obligación civil (Bolonia, Publicaciones del Real Colegio de España).

Baraona GonzÁlez, Jorge (2006): "Peculiaridades de la culpa del profesional liberal", en: Revista Anales Derecho UC (№ 1), pp. 27-55.

BarendreCht, Maurits et al. (2007): Principles of European Law. Service Contracts (PEL SC) (Oxford, Oxford University Press).

Barros Bourie, Enrique (2012): "Los contratos de servicios ante la doctrina general del contrato: la virtualidad analógica de las reglas sobre el mandato", en: Elorriaga, Fabián (ed.), Estudios de Derecho Civil VII (Santiago, Abeledo Perrot), pp. 325-340.

Beluche Rincón, Iris (2015): "El contrato de servicios: el derecho del cliente a desistir de forma unilateral", en: Revista de Derecho Civil (Vol. II, № 2), pp. 69-126. 
Brantt Zumarán, María Graciela y Mejías Alonzo, Claudia (2016): "El derecho supletorio del contrato de servicios en el código civil chileno: Insuficiencia de las reglas del mandato y del arrendamiento", en: Revista de Derecho de la Pontificia Universidad Católica de Valparaíso (Nº XLVI), pp. 71-103.

Cabanillas Sánchez, Antonio (1993): Las obligaciones de actividad y de resultado (Barcelona, Bosch Editor)

Contardo González, Juan Ignacio (2013): "Comentario al artículo 40", en: Barrientos, Francisca (coord.), La protección de los derechos de los consumidores. Comentarios a la Ley de protección a los derechos de los consumidores (Santiago, Thomson Reuters), pp. 851-865.

Crespo Mora, María Carmen (2013): "Las obligaciones de medios y de resultado de los prestadores de servicios en el DCFR", en Indret ( $\left.\mathrm{N}^{\circ} 2\right)$, pp. 1-45.

(2015): "Las obligaciones de medios y de resultado: recepción de la distinción por la propuesta CESL", en: Revista Jurídica Universidad Autónoma de Madrid ( $N^{\circ} 3$ ), pp. 91-104.

De Barrón Arniches, Paloma (2008): "Cuestiones sobre el contrato de servicios diseñado en el Marco Común de Referencia", en: InDret ( $\left.N^{\circ} 3\right)$, pp. 1-28.

(2011): "El contrato de servicios y la propuesta de modernización del Código Civil español", en: Boletín del Ministerio de Justicia (Año LXV, No 2134), pp. 1-15.

(2012): "Normas aplicables a los contratos de servicios en general IV.C.2:107", en: Vaquer, Antoni et al. (eds.), Derecho Europeo de Contratos, Libros II y IV del Marco Común de Referencia (Barcelona, Atelier Civil), pp. 1153-1205.

Díez-Picazo y Ponce de León, Luis (2007): Fundamentos del derecho civil patrimonial I. Introducción. Teoría del contrato, $6^{\text {a }}$ edición (Madrid, Thomson Civitas).

(2008): Fundamentos del derecho civil patrimonial II. Las relaciones obligatorias, $6^{\text {a }}$ edición (Madrid, Thomson Civitas).

EIDENmülleR, Horst et al. (2009): "El marco común de referencia para el Derecho privado europeo. Cuestiones valorativas y problemas legislativos", en: Anuario de Derecho Civil (Vol. 62, No 4), pp. 1461-1522.

Escartín Ipléns, José Antonio (2012): "El contrato de servicios", en: AA.VV., Autonomía de la voluntad en el Derecho privado. Estudios en conmemoración del 150 aniversario de la Ley del Notariado (Madrid, Consejo General del Notariado, Wolters Kluwer), Tomo III, pp. 603-659. 
FerRer RibA, Josep (2012): "Vicissituds en la prestació de serveis: deures de cooperació, instruccions i modificacions del contracte", en: Institut de Dret Privat Europeu i Comparat de la Universitat de Girona (edit.), Contractes, responsabilitat extracontractual $i$ altres fonts d'obligacions al Codi Civil de Catalunya (Girona, Materials de les Setzenes Jornades de Dret Català a Tossa), pp. 227-238.

Fuertes-Planas Aleix, Cristina (2008): "Deberes y responsabilidad del hombre", en: Hoyo, María Isabel (edit.), Modalidades de Responsabilidad (Madrid, Dykinson).

Gálvez Criado, Antonio (2008): La relevancia de la persona en los contratos de obra y servicios (especial estudio del derecho de desistimiento) (Valencia, Tirant lo Blanch).

JiMÉneZ Horwitz, Margarita (2012): "La distinción entre los contratos de obras y de servicios en el derecho español (estudio comparado con el derecho alemán)", en: Anuario de Derecho Civil (Vol. 65, № 2), pp. 551-584.

Jordano Fraga, Francisco (1991): "Obligaciones de medios y de resultado (a propósito de alguna jurisprudencia reciente)", en: Anuario de Derecho Civil (Vol. 44, № 1), pp. 5-96.

KLEIN, Michele (1997): El desistimiento unilateral del contrato (Madrid, Editorial Civitas S.A.).

Loos, Marco (2011): "Service Contracts", en: Hartkamp, Arthur et al. (eds.), Towards a European Civil Code (Alphen aan den Rijn, Wolters Kluwer), pp. 757-785.

Meza Barros, Ramón (2010): Manual de Derecho de civil. De las fuentes de las obligaciones (Santiago, Editorial Jurídica de Chile), Tomo I.

Moreno Quesada, Bernardo (1976): "Problemática de las obligaciones de hacer", en: Revista de Derecho Privado (Vol. 60, № 6), pp. 467-502.

Ortega Díaz, Juan Francisco (2008): "Hacia un concepto clarificador de servicio. El contrato de servicios como tipo contractual general", en: Revista Crítica de Derecho Inmobiliario (Año 84, No 705), pp. 221-268.

Peñallillo Arévalo, Daniel (2011): Obligaciones. Teoría general y clasificaciones. La resolución por incumplimiento, reimpresión primera edición (Santiago, Editorial Jurídica de Chile).

PINDYCK, Robert y Rubinfeld, Daniel (2009): Microeconomía (Traducc. Esther Rabasco y Luis Toharia, Madrid, Pearson Educación, S.A.). 
Pizarro Wilson, Carlos (2014): "El contrato médico. Calificación, contenido y responsabilidad", en: Revista Chilena de Derecho (Vol. 41, No 3), pp. 825-843.

Rodríguez Pinto, María Sara (2014): "Responsabilidad por incumplimiento de contratos de servicios. La protección del consumidor y del cliente por prestaciones defectuosas", en: Revista Chilena de Derecho (Vol. 41, № 3), pp. 791-823.

San Martín Neira, Lilian (2009): "Sobre la naturaleza jurídica de la 'cooperación' del acreedor en el cumplimiento de la obligación: la posición dinámica del acreedor en la relación obligatoria, como sujeto no sólo de derechos sino también de cargas y deberes", en: Revista de Derecho Universidad de Concepción ( $\left.N^{\circ} 225-226\right)$, pp. 135-196.

(2015): "Algunas consideraciones sobre el contrato para la confección de obra material. Problemas derivados de su configuración típica", en: Vidal, Álvaro et al. (editores), Estudios de Derecho Civil X (Santiago, Thomson Reuters), pp. 751-771.

SCHUlzE, Reiner (2006): "Deberes precontractuales y conclusión del contrato en el Derecho Contractual Europeo", en: Anuario de Derecho Civil (Vol. 59, $N^{0} 1$ ), pp. 29-58.

Severin Fuster, Gonzalo (2014): Los contratos de servicio: su construcción como categoría contractual y el derecho del cliente al cumplimiento específico (Tesis doctoral Universidad Autónoma de Madrid, inédita).

Stitchkin Branover, David (2009): El mandato civil (Santiago, Editorial Jurídica de Chile).

TJong TIIn TAi (2010): "Services as Product: Commodification of Contracts in European Private Law", en: TISCO Working Paper on Banking, Finance and Services ( $\mathrm{N}^{\circ} 7$ ), pp. 1-23.

Trigo García, María Belén (1999): Contratos de servicios. Perspectiva jurídica actual (Granada, Comares).

Valpuesta Gastaminza, Eduardo (2011): "Capítulo 8. Libro IV. C. Servicios", en: Valpuesta, Eduardo (coord.), Unificación del Derecho Patrimonial Europeo. Marco común de referencia y Derecho español (Barcelona, Bosch), pp. 255-291.

Vaquer Aloy, Antoni (2011): La armonización del derecho de obligaciones y de sucesiones en siglo XXI (Lima, Jurista Editores).

Vidal Olivares, Álvaro (2000): "La construcción de la regla contractual en el derecho civil de los contratos", en: Revista de Derecho de la Universidad Católica de Valparaíso ( No 21), pp. 209-227. 
Villanueva Lupión, Carmen (2009a): El Servicio como objeto de tráfico jurídico (Madrid, La Ley). (2009b): Los contratos de servicios (Madrid, La Ley).

WAHL, Jorge (2006): "Responsabilidad profesional de los constructores y promotores inmobiliarios", en: Revista Anales Derecho UC ( $\left.\mathrm{N}^{\circ} 1\right)$, pp. 7-25.

JURISPRUDENCIA CITADA

Hernández con Rodríguez (2009): Corte Suprema 9 marzo de 2009 (acción de resolución de contrato), en: www.westlawchile.cl CL/JUR/8435/2009.

Pepe Pizza con Lazcano (2009): Corte Suprema 13 de agosto de 2009 (acción de resolución de contrato), en: www.westlawchile.cl Identificador: 42482. 